\title{
Review Kinetika Reaksi Pembuatan Sabun dan Pemurnian Gliserol dari Limbah Alkali Sabun
}

\author{
Jabosar Ronggur Hamonangan Panjaitan $1^{1^{*}}$ \\ ${ }^{1}$ Program Studi Teknik Kimia Institut Teknologi Sumatera \\ Jl. Terusan Ryacudu Way Huwi Lampung Selatan 35365 Lampung \\ *jabosar.panjaitan@tse.itera.ac.id \\ DOI: https://doi.org/10.21107/rekayasa.v14i2.10626
}

\begin{abstract}
Soap is a product that commonly used as a cleanser and can be made through a saponification reaction between fat and base with glycerol as byproduct. The reaction kinetics of soap production is the study of how fast the soap production and it is an important part in reactor modeling and the optimization of operating conditions. On the other hand, glycerol is a byproduct of soap production which can be applied into various derivative products so that the glycerol purification process from soap production process is important to do. This review discusses the reaction kinetics of soap production and glycerol purification from alkaline soap waste. In general, the kinetics curve of the soap-making reaction consists of three stages, namely the induction period, the constant velocity period and the decreasing velocity period where the base concentration in the soaping reaction was related to the reaction rate. The lower base concentration used, the soap production reaction will slower. The soap production reaction had low activation energy and identified as second order reaction. In the process of purifying glycerol from alkaline soap waste, three main stages were generally used, namely neutralization, alcohol separation and glycerol purification.
\end{abstract}

Keywords : glycerol, byproduct, reaction kinetics, soap production

\section{INTRODUCTION}

Sabun adalah sejenis surfaktan yang dapat diproduksi dari bahan alam dan diaplikasikan sebagai produk pembersih seperti untuk menghilangkan germs, contaminants and dirt (Oyekunle et al., 2021). Hal ini dikarenakan sabun merupakan molekul yang memiliki gugus hidofobik dan hidrofilik sehingga sabun dapat berikatan dengan gugus hidrofobik debu dan gugus hidrofilik senyawa polar seperti air untuk menghilangkan debu (Lin et al., 2005). Sabun dapat dibuat dari animal fat dan basa untuk memproduksi sabun, air dan gliserol (Maotsela et al., 2019).

Gliserol adalah senyawa organik dengn rumus kimia $\mathrm{C}_{3} \mathrm{H}_{8} \mathrm{O}_{3}$ yang memiliki sifat biodegradasi, tidak berwarna, higroskopik, tidak beracun, tidak berbau, transparan, and larutan kental. Gliserol dapat diproduksi dari berbagai proses seperti transesterifikasi, saponifikasi, hidrolisis asam lemak, dan fermentasi mikrobial (Dhabhai, 2016). Gliserol

\section{Article History:}

Received: April, 19 ${ }^{\text {th }}$ 2021; Accepted: June, $27^{\text {th }} 2021$

Rekayasa ISSN: 2502-5325 has been Accredited by Ristekdikti (Arjuna) Decree: No. 23/E/KPT/2019 August 8th, 2019 effective until 2023 dapat digunakan untuk membuat produk - produk hasil fermentasi seperti asam - asam organik dan bioetanol. Akan tetapi, penggunaan gliserol ini menjadi terbatas karena beberapa produksi gliserol yang merupakan produk samping mengandung berbagai pengotor didalamnya. Gliserol mentah sebagai produk samping dari pembuatan biodiesel misalnya mengandung berbagai pengotor seperti methanol, air, sabun, asam lemak bebas, garam, charcoal dan senyawa kimia lain dari katalis (Kumar et al., 2019).

Sabun dapat dibuat melalui reaksi saponifikasi. Reaksi saponifikasi merupakan reaksi antara lemak atau gliserida dengan basa (Iriany et al., 2019). Penggunaan basa dalam pembuatan sabun dapat mempengaruhi tipe sabun yang dihasilkan. Potassium alkali dapat digunakan untuk membuat sabun cair sedangkan sodium alkali dapat digunakan untuk membuat sabun padat. Reaksi

\section{Cite this as:}

Panjaitan, J.R.H. (2021). Review Kinetika Reaksi Pembuatan Sabun dan Pemurnian Gliserol dari Limbah Alkali. Rekayasa 14 (2). 200-206. doi: https://doi.org/10.21107/rekayasa.v14i2.10626 (c) 2021 Jabosar Ronggur Hamonangan Panjaitan 
saponifikasi termasuk kedalam reaksi autokatalitik karena produk sabun yang terbentuk dapat melarutkan alkali dan mendispersikan lemak menjadi suspense koloid. (Saxton et al., 2013).

Pengetahuan mengenai kinetika dan termodinamika reaksi merupakan bagian penting untuk memahami reaksi (Raheem et al., 2020). Kinetika reaksi merupakan ilmu yang mempelajari seberapa cepat reaksi berlangsung. Parameter parameter kinetika reaksi merupakan bagian penting untuk pemodelan reaktor dan optimisasi kondisi operasi (Heydari et al., 2015).

Beberapa penelitian telah meneliti kinetika reaksi pembuatan sabun. Almilly (2014) meneliti tentang kinetika saponifikasi olein dan stearin menggunakan $\mathrm{NaOH}$ dengan variasi konsentrasi $\mathrm{NaOH}$, suhu, dan laju pengadukan. Produk yang diperoleh dianalisis dengan menggunakan refractometer untuk mengukur indeks refraksi. Hasibuan et al (2019) meneliti pengaruh tipe pengaduk terhadap proses dan kinetika penyabunan.

Asiagwu (2013) telah meneliti kinetika saponifikasi minyak Treculia africana yang menggunakan sumber alkali local dan Protasova et al (2021) yang meneliti identifikasi parameter saponifikasi sebagai suatu reaksi bertahap yang dikarakterisasi dengan model reaksi. Selain itu, beberapa penelitian telah dilakukan untuk memurnikan gliserol dari hasil samping produksi sabun. Israel et al (2008) meneliti tentang recovery gliserol dari berbagai spent lye from soap manufacturing companies. Efeovbokhan et al (2012) meneliti tentang recovery glycerol dari produksi sabun dengan bahan baku minyak kelapa sawit. Sedangkan Ikiensikimama \& Josiah (2005) meneliti pengaruh suhu dan waktu pada recovery gliserol menggunakan $\mathrm{Al}_{2}\left(\mathrm{SO}_{4}\right)_{3}$ yang diikuti dengan proses evaporasi. Oleh sebab itu, pada review ini akan dibahas secara spesifik mengenai kinetika reaksi pembuatan sabun dan pemunian gliserol dari hasil samping produksi sabun.

\section{MODEL KINETIKA PRODUKSI SABUN}

Model kinetika sabun didasarkan atas reaksi pembuatan sabun (saponifikasi) seperti Gambar 1.

Berdasarkan Gambar 1, persamaan kinetika pembuatan sabun bisa diturunkan melalui model reaksi sesuai penelitian Almilly (2014) dan Hasibuan et al (2019) yang dilihat pada Tabel 1.

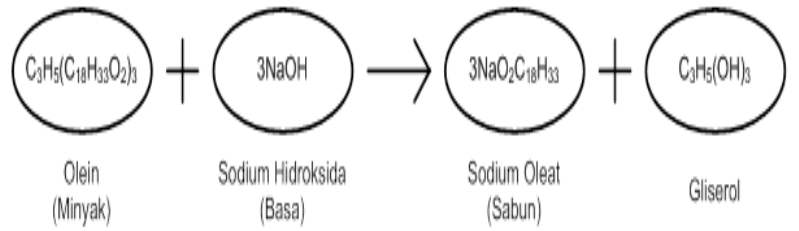

Gambar 1. Reaksi Pembuatan Sabun

Berdasarkan Tabel 1 dapat dilihat bahwa skema reaksi antara Almilly (2014) dan Hasibuan et al (2019) memiliki perbedaan konsep dalam koefisien stoikiometri reaksi. Almilly (2014) tidak menguraikan lebih lanjut koefisien stoikiometri basa menjadi tiga. Sedangkan Hasibuan et al (2019) telah menggunakan nilai tiga pada koefisien stoikiometri basa. Perbedaan inilah yang membuat persamaan laju reaksi menjadi berbeda yang dalam penurunan model kinetika reaksi lebih lanjut akan menghasilkan model kinetika pembuatan sabun yang berbeda. Almilly (2014) menurunkan persamaan laju reaksi penyabunan menggunakan variable konversi bahan baku minyak $\left(\mathrm{X}_{\mathrm{A}}\right)$ sehingga akhirnya diperoleh model kinetika pembuatan sabun sesuai Tabel 1. Di sisi lain, Hasibuan et al (2019) mensubsitusi variable konsentrasi minyak $\left(C_{A}\right)$ menjadi variable konsentrasi basa $\left(C_{B}\right)$ dimana $C_{A}$ sama dengan $1 / 3$. $C_{B}$ sehingga akhirnya diperoleh model kinetika pembuatan sabun yang lebih sederhana sesuai Tabel 1.

Tabel 1. Perbandingan Model Kinetika Pembuatan Sabun

\begin{tabular}{|c|c|c|}
\hline Referensi & Almilly (2014) & $\begin{array}{l}\text { Hasibuan et al } \\
(2019)\end{array}$ \\
\hline Skema Reaksi & $A+B \leftrightarrow C+D$ & $A+3 B \leftrightarrow 3 C+D$ \\
\hline $\begin{array}{l}\text { Persamaan Laju } \\
\text { Reaksi }\end{array}$ & $-r_{A}=k \cdot C_{A} \cdot C_{B}$ & $-r_{A}=k C_{A^{a}}^{a}\left(1 / 3 \cdot C_{B}\right)^{b}$ \\
\hline $\begin{array}{l}\text { Model Kinetika } \\
\text { Pembuatan } \\
\text { Sabun }\end{array}$ & $\operatorname{In}\left[\frac{C_{B o}-3 x_{A} C_{A o}}{1-x_{A}}\right]^{\frac{1}{\left(C_{B o}-3 C_{A o}\right)}}=k t$ & $\begin{array}{c}\operatorname{In}-r_{A} \\
=n \operatorname{In} C_{B}+\operatorname{In} k\end{array}$ \\
\hline
\end{tabular}

Berdasarkan Almilly (2014) diperoleh bahwa orde reaksi penyabunan adalah orde dua. Hal ini sesuai dimana reaksi saponifikasi pada umumnya berada pada reaksi orde dua. Dari analisis refraktometer diperoleh nilai indeks refraksi menurun ketika nilai konversi meningkat dimana fenomena ini berkaitan dengan densitas medium reaksi. Disaat larutan basa $\mathrm{NaOH}$ dicampur kedalam minyak, densitas minyak akan meningkat dan indeks refraksi menurun. Kemudian disaat sabun terbentuk, densitas minyak akan menurun dan indeks refraksi akan meningkat. Pengaruh konsentrasi $\mathrm{NaOH}$ pada Almilly (2014) menunjukkan bahwa konsentrasi $\mathrm{NaOH}$ berhubungan dengan laju reaksi dimana semakin rendah konsentrasi $\mathrm{NaOH}$ yang digunakan maka akan menyebabkan semakin lambatnya laju reaksi. 
Hal yang juga sama ditemukan oleh Asiagwu (2013) dimana semakin rendah konsentrasi $\mathrm{KOH}$ yang digunakan akan membuat laju reaksi semakin lambat. Suhu juga dapat mempengaruhi laju reaksi, dimana dari hasil penelitian Almilly (2014) diperoleh bahwa pengaruh suhu yang dinyatakan dengan persamaan Arrhenius didapat nilai energi aktivasi yang rendah, sehingga reaksi dapat berjalan cepat pada suhu reaksi yang rendah.

Pandangan lain terhadap kinetika reaksi pembuatan sabun telah dilaporkan oleh Protasova et al (2021). Pada penelitiannya diperoleh bahwa proses saponifikasi sabun sesuai urutan waktu dapat digambarkan ke dalam kurva kinetika reaksi. Kurva kinetika reaksi saponifikasi sabun ini terbagi atas tiga tahap yaitu periode induksi, periode kecepatan konstan dan periode kecepatan menurun. Pada tahap induksi laju reaksi saponifikasi bergantung dengan interaksi reaktan minyak dan alkali yang termasuk sistem heterogen yang saling sulit melarutkan. Oleh karena itu, pada tahap induksi perlu dilakukan beberapa tindakan seperti menaikkan suhu reaksi saponifikasi dan menambahkan emulsifier. Protasova et al (2021) menggunakan teknologi ultrasonik untuk meningkatkan proses intensifikasi pembuatan sabun. Teknologi ultrasonik pada proses pembuatan sabun dilakukan pada suhu $60^{\circ} \mathrm{C}$ dan $80^{\circ} \mathrm{C}$ yang meningkatkan konstanta laju reaksi penyabunan meningkat 1,8 kali lebih besar.

\section{Pengaruh Jenis Pengaduk Pada Kinetika Reaksi Pembuatan Sabun}

Penelitian Hasibuan et al (2019) telah meneliti pengaruh tipe pengaduk (paddle -2 blades, pitch blade turbine $45^{\circ}-2$ blades, paddle -4 blades, dan pitch blade turbine $45^{\circ}-4$ blades) terhadap kinetika reaksi pembuatan sabun. Tipe pengaduk ini dapat dilihat pada Gambar 2.

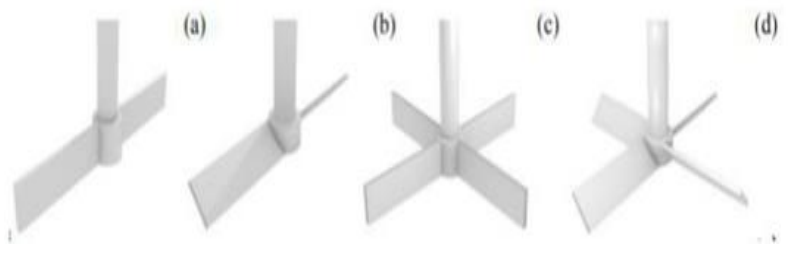

Gambar 2. Berbagai Jenis Pengaduk

(Hasibuan et al. 2019)

a) paddle -2 blades; b) pitch blade turbine $45^{\circ}-2$ blades;

c) paddle -4 blades; d) pitch blade turbine $45^{\circ}-4$ blades

Beberapa parameter reaksi telah diuji Hasibuan et al (2019) untuk mengetahui pengaruh jenis pengaduk terhadap konsentrasi alkali, laju reaksi, dan parameter kinetika reaksi. Pada tiap jenis pengaduk konsentrasi alkali turun setiap bertambahnya waktu. Konsentrasi alkali paling rendah diakhir waktu reaksi adalah reaktor yang menggunakan pengaduk pitch blade turbine $45^{\circ}-$ 4 blades. Konsentrasi alkali yang rendah merupakan tanda bagi kualitas sabun yang baik sesuai dengan SNI 06-3532-1994 (BSN, 1994). Hal ini disebabkan karena pengaduk tipe pitch blade turbine $45^{\circ}-4$ blades menghasilkan proses pengadukan yang paling baik sehingga tumbukan antar partikel reaktan akan semakin baik untuk membentuk produk. Pengaruh variasi jenis pengaduk terhadap laju reaksi menunjukkan bahwa laju reaksi semakin menurun seiring dengan bertambahnya waktu dan tipe pengaduk tidak memiliki pengaruh yang signifikan dengan laju reaksi. Pengaruh variasi jenis pengaduk terhadap parameter kinetika reaksi dalam Tabel 2. Berdasarkan Tabel 2 dapat dilihat bahwa tipe pengaduk memberikan nilai parameter kinetika reaksi yang beragam.

Tabel 2. Nilai orde reaksi dan konstanta reaksi terhadap berbagai jenis pengaduk (Hasibuan et al, 2019)

\begin{tabular}{lll}
\hline Tipe Pengaduk & $\begin{array}{l}\text { Orde } \\
\text { Reaksi }\end{array}$ & Konstanta Reaksi \\
\hline Paddle -2 blades & 3,531 & 0,885 \\
pitch blade turbine & 3,569 & 8,591 \\
$45^{\circ}-2$ blades & & \\
$\begin{array}{l}\text { Paddle }-4 \text { blades } \\
\text { pitch blade turbine }\end{array}$ & 4,305 & 8,667 \\
$45^{\circ}-4$ blades & & 27,151 \\
\hline
\end{tabular}

\section{Komposisi Limbah Alkali Sabun}

Pembuatan sabun dilakukan dengan menggunakan reaksi saponifikasi dimana pada proses ini minyak direaksikan dengan larutan alkali untuk menghasilkan sabun dan gliserol. Pada prakteknya diakhir proses saponifikasi akan terbentuk dua produk yaitu sabun (produk lapisan atas) dan limbah larutan alkali (produk lapisan bawah) (Ikiensikimama \& Josiah, 2006). Pada limbah larutan alkali inilah terkandung gliserol. Komposisi limbah alkali sabun secara umum terdiri dari gliserol (6-16\%), salt (10 - 12\%), soda api $(0,3-0,8 \%)$, total asam lemak (0,4\%) dan air (39-40\%). Komposisi gliserol pada berbagai bahan dapat dilihat pada Tabel 3 (Israel et al., 2008). Berdasarkan Tabel 3 dapat dilihat bahwa potensi komposisi gliserol yang mencapai $16 \%$ pada limbah alkali sabun sangat potensial untuk di rekoveri. 
Tabel 3. Kandungan Gliserol pada Berbagai Bahan (Israel et al., 2008)

\begin{tabular}{ll}
\hline Bahan & Komposisi Gliserol (\%) \\
\hline $\begin{array}{l}\text { Spent Soap Lye (Limbah } \\
\text { Alkali Sabun) }\end{array}$ & $6-16$ \\
Treated Lye: Acid, Alkaline & $5-7,8-10$ \\
Semi - Crude Glycerin & $30-45$ \\
Crude Glycerin & $80-84$ \\
Bleached Crude Glycerin & $85-91$ \\
Purified Glycerin & 92 \\
\hline
\end{tabular}

\section{Pemurnian Gliserol dari Limbah Alkali Sabun}

Secara umum proses pemurnian gliserol dari industri sabun dapat diringkas sesuai dengan Ardi et al. (2015). Dimana pada tahap pemurniannya gliserol melewati beberapa tahapan umum seperti netralisasi, pemisahan alkohol dan pemurnian gliserol. Pada tahap netralisasi, substansi nongliserol seperti asam lemak dan salts dapat dipisah. Selanjutnya alkohol atau methanol dapat dipisah dengan gliserol dengan menggunakan metode evaporasi. Sedangkan pada tahap akhir yaitu pemurnian gliserol dapat dilakukan dengan menggunakan berbagai metode seperti destilasi vakum, ion exchange, membran dan adsorpsi. Beberapa penelitian telah dilakukan untuk memurnikan gliserol dari limbah alkali sabun. Berbagai skema dalam pemurnian gliserol dari limbah alkali sabun dapat dilihat pada Gambar 4.

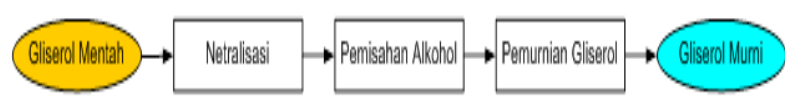

Gambar 3. Proses umum pemurnian gliserol

Gambar 4 merupakan penjabaran rinci dari Gambar 3. Sesuai Gambar 4 tahap pertama dalam proses pemurnian gliserol adalah netralisasi. Proses netraliasasi ini dapat dilakukan dengan mereaksikan gliserol mentah dengan senyawa asam $(\mathrm{HCl})$ dan basa $(\mathrm{NaOH})$. Gliserol mentah yang direaksikan dengan asam digunakan untuk menghilangkan sisa katalis dan sabun pada gliserol mentah. Sedangkan reaksi dengan senyawa basa akan menghasilkan salts dan air. Tahap kedua dalam pemurnian gliserol pada Gambar 3 adalah pemisahan alkohol yang dapat dilakukan dengan menggunakan proses

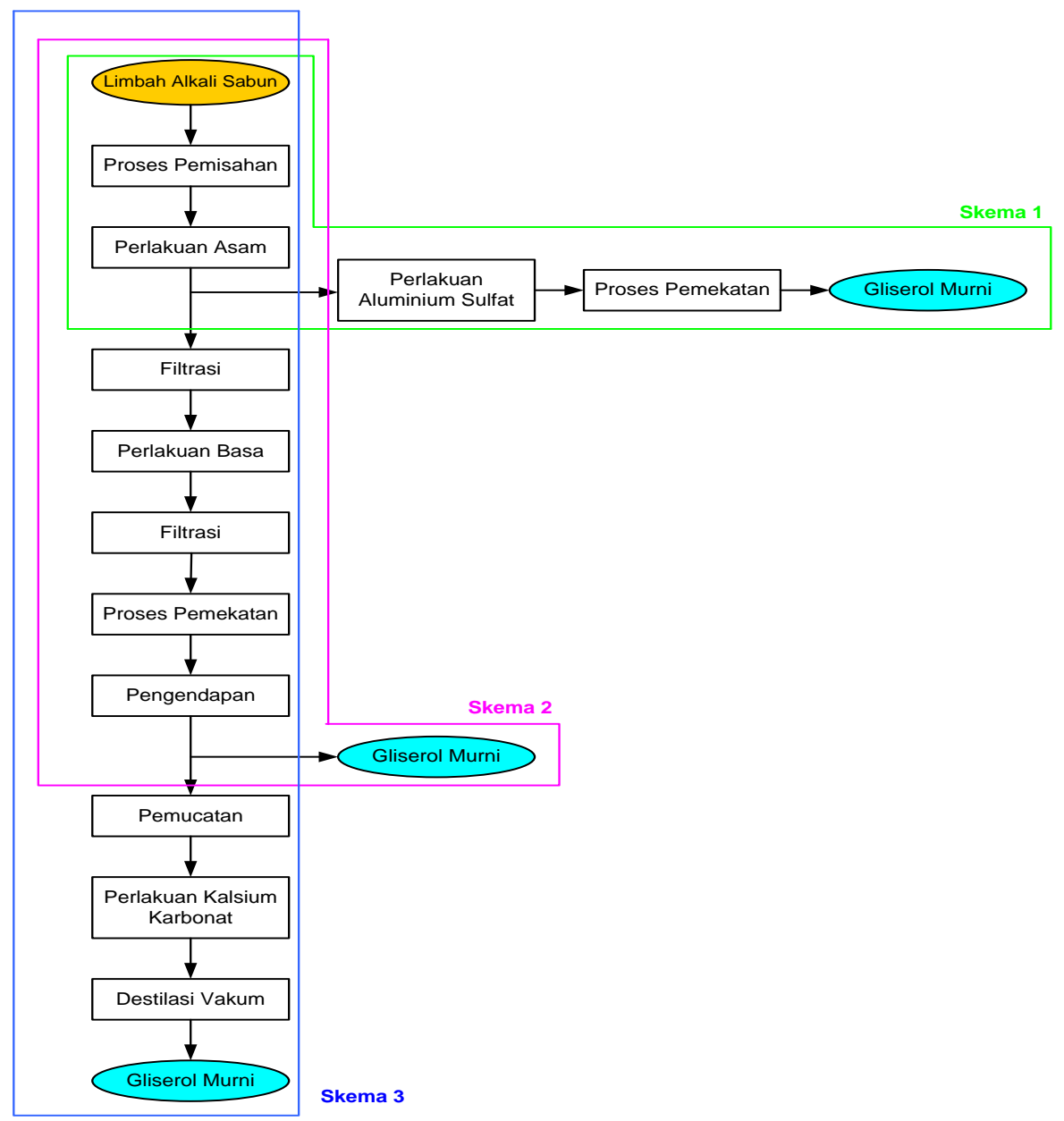

Gambar 4. Berbagai skema pemurnian gliserol dari limbah alkali sabun 
pemekatan sesuai dengan Gambar 4. Proses pemekatan ini dapat dilakukan dengan pemanasan maupun evaporasi untuk menguapkan alkohol. Sedangkan pada tahap ketiga adalah tahap pemurnian gliserol. Dimana pada tahap ini berbagai metode pemurnian dapat dilakukan seperti pada Gambar 4 di alur Skema 3, proses pemurnian gliserol dilakukan dengan menggunakan metode pemucatan/bleaching.

Berbagai skema dalam proses pemurnian gliserol dari limbah alkali sabun dapat dilihat pada Gambar 4. Berdasarkan Gambar 4, proses pemurnian gliserol dari limbah alkali sabun dapat dibagi atas tiga skema dimana Skema 1 didasarkan pada penelitian Ikiensikimama \& Josiah (2006), Skema 2 didasarkan pada penelitian Efeovbokhan et al. (2012), dan Skema 3 didasarkan pada penelitian Israel et al. (2008).

Pada Skema 1 setelah limbah alkali sabun/gliserol mentah diberi perlakuan asam, gliserol mentah lalu diberi perlakuan aluminium sulfat. Aluminium sulfat pada proses ini berfungsi sebagai reagen untuk membentuk sodium sulfat $\left(\mathrm{Na}_{2} \mathrm{SO}_{4}\right)$ sehingga mengurangi kandungan salts dari gliserol mentah. Selanjutnya gliserol mentah akan masuk ke dalam proses pemekatan menggunakan metode evaporasi untuk mendapatkan gliserol murni.

Pada Skema 2 dan 3, gliserol mentah melalui berbagai proses berurutan yang sama, namun perbedaan terdapat setelah proses pemekatan dan pengendapan. Dimana setelah proses ini Gliserol murni diperoleh menurut Skema 2, sedangkan pada Skema 3 gliserol murni masih harus melalui proses bleaching menggunakan bleaching earth (3\%) dan asam sulfat $(10 \mathrm{ml})$. Produk bleaching pada Skema 3 kemudian direaksikan dengan kalsium karbonat untuk proses netralisasi dan destilasi vakum yang kemudian diperoleh gliserol yang lebih murni.

\section{Metode Potensial dalam Pemurnian Gliserol}

Proses pemurnian gliserol dari limbah alkali sabun sebagai tahap ketiga sesuai dengan Gambar 3 tidak hanya terbatas dapat dilakukan dengan menggunakan bleaching earth sesuai Israel et al. (2008). Pada industri bahan bakar alternatif seperti biodiesel yang juga menghasilkan gliserol sebagai produk samping telah diteliti berbagai proses pemurnian gliserol. Beberapa penelitian cukup banyak dilakukan untuk memurnikan gliserol seperti destilasi vakum, adsorpsi ion exchange, adsorpsi menggunakan karbon aktif, teknologi membran, dan juga gabungan dari beberapa metode pemurnian.

Gliserol merupakan senyawa kimia yang cukup rentan terhadap panas sehingga dalam pemurnian nya metode destilasi vakum dapat digunakan sebagai metode pemurnian gliserol (Xiao et al., 2013; Gerpen, 2005). Pada suhu lebih dari $200^{\circ} \mathrm{C}$ gliserol dapat mengalami proses polimerisasi menjadi polyglycerol dan pada suhu diatas $160^{\circ} \mathrm{C}$ gliserol dapat mengalami dehidrasi pada kondisi asam (Surrod \& Pattamaprom, 2011). Metode pemurnian gliserol dengan teknik ion exclusion dapat digunakan untuk menghilangkan berbagai impuritis seperti asam lemak, garam anorganik dan ion bebas (Asher \& Simpson, 1956). Bahkan aplikasi ion exchange unit dari limbah sabun secara komersial telah dibangun pada pabrik Lever Brother Company di Los Angeles. Pabrik ini sudah beroperasi sejak 1951 dan memiliki kapasitas pemurnian hingga 26.600 lbs gliserol mentah perhari (Ardi et al., 2015).

Adsorpsi dengan menggunakan karbon aktif sebagai metode pemurnian gliserol digunakan untuk mengurangi warna, asam lemak dan beberapa komponen lainnya. Manosak et al. (2011) dalam penelitiannya diketahui bahwa semakin tinggi konsentrasi karbon aktif yang dipakai akan meningkatkan penghilangan warna pada gliserol. Aplikasi teknologi membran dalam pemurnian gliserol telah dikembangkan oleh EET Corporation dengan paten High Efficiency Electro-Pressure Membrane $\left(\right.$ HEEPM $\left.^{\top M}\right)$. Pada prosesnya unit membrane yang digunakan merupakan konfigurasi dari nanofiltrasi dengan atau tanpa unit reverse osmosis yang bersinergi pada satu unit operasi (Sdrula, 2010).

\section{KESIMPULAN}

Pada review ini dibahas tentang kinetika reaksi pembuatan sabun dan pemurnian gliserol dari limbah alkali sabun. Model kinetika reaksi pembuatan sabun didasarkan atas jenis skema reaksi yang dipakai dimana kinetika reaksi penyabunan memiliki nilai energi aktivasi yang rendah dan orde reaksi bernilai dua. Secara umum, kurva kinetika reaksi pembuatan sabun terdiri atas tiga tahap yaitu periode induksi, periode kecepatan konstan dan periode kecepatan menurun. Konsentrasi basa pada reaksi penyabunan berhubungan dengan laju reaksi dimana semakin rendah konsentrasi basa yang digunakan maka akan menyebabkan semakin lambatnya reaksi 
penyabunan. Pengaduk tipe pitch blade turbine $45^{\circ}$ - 4 blades merupakan pengaduk yang menghasilkan proses pengadukan paling baik dalam reaksi penyabunan. Proses pemurnian gliserol dari limbah alkali sabun terdiri atas tiga tahapan utama yaitu netralisasi, pemisahan alcohol dan pemurnian gliserol. Pada tahap netralisasi limbah alkali sabun dapat direaksikan dengan asam maupun basa untuk menghilangkan sisa katalis dan sabun. Pada tahap pemisahan alcohol dapat dilakukan dengan evaporasi untuk menghilangkan sisa alcohol. Sedangkan pada tahap pemurnian gliserol, griserol dapat dimurnikan dengan barbagai proses seperti destilasi vakum, adsorpsi ion exchange, adsorpsi menggunakan karbon aktif, teknologi membran dan gabungan dari beberapa metode pemurnian.

\section{DAFTAR PUSTAKA}

Almilly, R.F.K (2014). Kinetics of the saponification of mixed fats consisting of olein and stearin, Journal of Engineering, 20(6), 144-159.

Ardi, M.S., Aroua, M.K., \& Awanis-Hashim, N. (2015). Progress, prospect and challenges in glycerol purification process: A review. Renewable and Sustainable Energy Reviews, 42, 1164 - 1173. https://doi.org/10.1016/j.rser.2014.10.091

Asher, D.R. \& Simpson, D.W. (1956). Glycerol purification by ion exclusion. J. Phys. Chem, 60(5),

18-21.

https://doi.org/10.1021/j150539a002

Asiagwu, A.K (2013). Kinetics of saponification of Treculia Africana oil using a locally sourced alkaline, IJRRAS, 14 (3), 623 - 629.

Badan Standarisasi Nasional. (1994). Sabun Mandi, SNI 06-3532-1994.

Busby, G.W. \& Grosvenor, D.E. (1952). The purification of glycerin by ion-exchange. Journal of The American Oil Chemists Society, 29, 318320.

Dhabhai, R., Ahmadifeijani, E., Dalai, A.K., \& Reaney, M. (2016). Purification of crude glycerol using a sequential physico-chemical treatment, membrane filtration, and activated charcoal adsorption. Separation and Purification Technology, 168, $101-106$. https://doi.org/10.1016/j.seppur.2016.05.030
Efeovbokhan, Enon, V., Anawe, Lucky, P.A., Adeeyo, Opeyemi, Obafunso, \& Aderonke, B. (2012). Recovery of glycerine from spent palm kernel soap and palm oil soap lye, International Journal of Engineering \& Technology IJET-IJENS, 12(2).

Gerpen, J.V. (2005). Biodiesel processing and production. Fuel Processing Technology, 86,1097-1107. https://doi.org/10.1016/j.fuproc.2004.11.005

Hasibuan, R., Parsaulian, R.R., Adventi, F., \& Manurung, R. (2019). Effect of impeller types on saponification reaction using stirred tank reactor, Abdimas Talenta, 4(2), 606 - 612. https://doi.org/10.32734/abdimastalenta.v4i2.4 $\underline{190}$

Heydari, M., Rahman, M., \& Gupta, R. (2015). Kinetic study and thermal decomposition behavior of lignite coal. International Journal of Chemical Engineering, 481739. https://doi.org/10.1155/2015/481739

Ikiensikimama, S.S. \& Josiah, P.N. (2006). Effect of reaction temperature and time on the recovery of glycerol from spent lye. Global Journal of Pure and Applied Sciences, 12(3), $373-376$.

Iriany, Sukeksi, L., Diana, V., \& Taslim. (2019). Preparation and characterization of coconut oil based soap with kaolin as filler. Journal of Physics: Conference Series (1542) 012046. https://doi:10.1088/1742-6596/1542/1/012046

Israel, A.U., Obot, I.B., \& Asuquo, J.E. (2008). Recovery of glycerol from spent soap lye by product of soap manufacture. E-Journal of Chemistry, 5(4), 940 - 945.

Kumar, L.R., Yellapu, S.K., Tyagi, R.D., \& Zhang, X. (2019). A review on variation in crude glycerol composition, bio-valorization of crude and purified glycerol as carbon source for lipid production. Bioresource Technology, 293, 122155.

https://doi.org/10.1016/j.biortech.2019.122155

Lin, B., McCormick, A.V., Davis, H.T., \& Strey, R. (2005). Solubility of sodium soaps in aqueous salt solution. Journal of Colloid and Interface Science, 291, $543 \quad-\quad 549$. https://doi.org/10.1016/j.jcis.2005.05.036 
Manosak, R., Limpattayanate, S., \& Hunsom, M. (2011). Sequential-refining of crude glycerol derived from waste used-oil methyl ester plant via a combined process of chemical and adsorption. Fuel Processing Technology, 92(1), 92-99.

https://doi.org/10.1016/j.fuproc.2010.09.002

Maotsela, T., Danha, G., \& Muzenda, E. (2019). Utilization of waste cooking oil and tallow for production of toilet "bath" soap. Procedia Manufacturing, 35, $541 \quad$ - 545. https://doi.org/10.1016/j.promfg.2019.07.008

Oyekunle, J.A.O., Ore, O.T., Ogunjumelo, O.H., \& Akanni, M.S. (2021). Comparative chemical analysis of Indigenous Nigerian Soaps with Conventional ones. Heliyon, 7, e06689. https://doi.org/10.1016/j.heliyon.2021.e06689

Protasova, N.N., Korchagin, M.V., Protasov, A.V., \& Korchagin, V.I., (2021). Analysis and synthesis of kinetic parameters of soap stock saponification stage in sunflower oil production. IOP Conference Series: Earth and Environmental Science, 640, 042015. https://doi:10.1088/1755$\underline{1315 / 640 / 4 / 042015}$

Raheem, I., Mohiddin, M.N.B., Tan, Y.H., Kansedo, J., Mubarak, N.M., Abdullah, M.O., \& Ibrahim, M.L. (2020). A review on influence of reactor technologies and kinetic studies for biodiesel application. Journal of Industrial and
Engineering Chemistry, 91, 54 - 68. https://doi.org/10.1016/j.jiec.2020.08.024

Saxton, K., Crosby, B. \& Dunn, K. (2013). Formulation of transparent melt and pour soaps without petroleum derivatives. $\mathrm{H}$-SC Journal of Science 2, Vol II.

Sdrula, N. (2010). A study using classical or membrane separation in the biodiesel process. Desalination, 250(3), 1070-1072. https://doi.org/10.1016/j.desal.2009.09.110

Surrod, T. \& Pattamaprom, C. (2011). Purification of glycerin by-product from biodiesel production using electrolysis process. Proceedings of The Second TSME International Conference on Mechanical Engineering. Krabi, Thailand, ID: 115141238.

Xiao Y, Xiao G, \& Varma A. (2013). A universal procedure for crude glycerol purification from different feedstocks in biodiesel production: experimental and simulation study. Industrial and Engineering Chemistry Research, 52(39), 14291-14296. https://doi.org/10.1021/ie402003u 